\title{
Information and Communication Technology in Family Practice
} in Croatia

\author{
Josipa Kern', Ozren Polašek ${ }^{1}$ \\ ${ }^{1}$ Andrija Stampar School of Public Health, Zagreb University Medical School, Croatia
}

Summary: Family practice was the first privatized part of the health care system in Croatia. Recently, $84 \%$ of family practices are privatized. Other $16 \%$ of them left within health centers. In order to assess current status of use of the information and communication technology (ICT) in family practice, physicians specializing in the family medicine, being also the postgraduate students of the University of Zagreb, School of Medicine in the year $2004 / 05$, have been surveyed. The sample consisted of 159 physicians. Some kind of information system (IS) exists in $62 \%$ of family practices under lease, $42 \%$ within health centers, and $91 \%$ of completely private offices. Having IS in their offices, physicians use it primarily for administration: reporting, prescriptions, sick leaves, referrals and for billing. Usage of ICT in medical work, electronic medical records, was found at about $50 \%$ of physicians. Doing research based on information stored in e-format, is conducting by $31 \%$ of physicians. Based on e-information $35 \%$ of physicians evaluate their work. About using e-sources of medical knowledge (bibliographic data bases, e-journals): $86 \%$ physicians from private offices, $79 \%$ physicians working within health centers, $60 \%$ physicians from offices under lease. Satisfaction with current information system is small $(19 \%)$. Their information needs are covered partially. $32 \%$ of physicians said they can get enough information by using their information system. $40 \%$ of physicians feel that ICT gave more efficiency to their work, and $25 \%$ of physicians feel their patients are more satisfied since the IS was put into function. Considering different types of practices - young physicians working in health centers are less satisfied with their ISs than the other two groups of physicians coming from private practice. Data security was practiced by using a password, physical protection, and by daily archiving of data.
Keywords: information system, family practice, electronic medical record, Internet, computer security, bibliographic databases, consumer satisfaction

\section{Introduction}

Family medicine is one of the main pillars of population health care in Croatia. Its role is very important in both, prevention and cure, for a predefined population. Willing to achieve, maintain and improve the quality of health care, family physicians need to record patients' data, do analyses, and have access to relevant information and knowledge relating to a problem. Considering the fact that data operability can be fully achieved only by use of information and communication technology (ICT), it is time indeed for such a technology to domesticate appropriately in practice of family medicine. Appropriateness of ICT in medicine and health means the application capable to give information needed to a physician or a nurse, but also to a wider community (if a family physician is obliged to give such an information, e.g. to public health, health insurance, secondary and tertiary health care, Ministry of Health etc.). Of course, all measures for data security and confidentiality should be applied. A family physician should expect to have a useful and user-friendly ICT application enabling to give an information promptly. The ICT application should be modular and scalable, able to be upgraded and improved in accordance with needs of users. It should include international standards, and be evaluated by both, health and ICT professionals [1].

Health professionals should be educated in using the ICT application, they should be aware of possibilities and limitations of such a technology and motivated for further development and improvements of their ICT-based system.
As a transitional country, Croatia started with privatization in the health care system in 1994. Family medicine practice was one of the first privatized parts of the health care system in Croatia. Recently, $84 \%$ of family medicine practices are privatized. Other 16\% left within health centers: $95 \%$ of privatized family practices are under lease (in offices and equipment owned by health centers; family practice pays for leasing) and $5 \%$ as completely private (in their own office, with their own equipment). Family practices have contracts with the Croatian Institute for Health Insurance (ClHI). According to the contract, the $\mathrm{ClHI}$ covers health care services by paying for patients pre-registered in the family practice (by payment "per capita"). There are some differences between different family practices in their obligations and their autonomy:

- practices within a health center (offices and equipment owned by a health center, the contract between the $\mathrm{ClHI}$ and health centers, health care providers are paid by health centers, some additionally paid health services the family practice can provide are not permitted; no autonomy atall),

-practices under lease (offices and equipment owned by a health center are leased by a family physician, the contract between the $\mathrm{ClHI}$ and a family physician, all financials are up to him/her, some additionally paid health services the family practice can provide are not permitted; limited autonomy),

-completely private family practice (offices and equipment owned by a family physician, the contract between $\mathrm{ClHI}$ and a family physician, all financials are up to him/her, some additionally paid health services the family practice can provide are permitted; autonomy).

Having privatized their practice, many family physicians started with bringing ICT-solutions to their offices. 
It is much less the case of family practices left within health centers, where family physicians have no opportunities for deciding what kind of ICT-solutions to buy. The questions are: what kind of ICTsolutions they have, are they satisfied with them, are they skilful enough in using ICT, and are there any differences between different status of family medical practices considering the kind of privatization and those not being privatized.

\section{ICT in the Croatian health care system}

The Croatian health care system started with the ICT application in late 60's [2]. Of course, applications were appropriate to the level of technological development and possibilities the Croatia has had then. Primary health care units organized in health centers, and hospitals, started in 1970 with IT-based administration in these institutions [3], [4]. The latest efforts in that direction within the health care system reform are attributed to the Ministry of Health and its document "Strategy and plan of the reform of the health care system and health insurance of the Republic Croatia" [5]. Considering the role of primary health care in the health care system, a special treatment has been given to development of ICT based solution for primary health care [6].

\section{Current status of IS in family medicine practice}

3.1. The basis for analysis of current status

In the analysis of the current status of informatization of family medicine practice (ICT skillfulness and using ICT, some medical informatics knowledge and readiness of medical doctors to accept and improve information systems in their offices), physicians specializing in family medicine, being also the postgraduate students at the University of Zagreb, Medical School, in the school-year $2004 / 05$, have been surveyed. The survey was anonymous and it was taken after the first, introductory medical informatics class.

The survey consisted of three modules: (a) questions about the physician (age, years of working in practice, sort of practice - office under lease, office in a health centre, completely private office), (b) questions on using of ICT, and, finally (c) on the information system installed in their office. This last module was taken only for physicians with computers in their offices and a certain ICT-based application installed on it.

\subsection{Results}

Table 1 shows a sample of primary health care physicians, postgraduate students in the school year 2004/2005 during the specialization in family medicine. All of them were working for several years as primary health care physicians. Most of the 159 physicians participating in the survey had their office under lease (117 of them), 28 of them had their offices within a health centre, and 14 had the completely private office. It can be perceived that practices within health centers are less computerized. Medical doctors working there are younger. They are (on average) 8 years younger than others, with 10 years shorter working period in practice. Completely private offices have been computerized in most cases $(91 \%)$.

Patterns of use of ICT are equal for all three groups of medical doctors: using e-mail was on the top, keeping on reading health portals was on the second place. Then searching medical literature through PubMed, Current Contents etc., and electronic journals like Croatian Medical Journal, British Medical Journal and alike follows. Differences in use of electronic sources of medical knowledge within physicians from the three types of offices are statistically significant (Chi-square test $p=0.043$ ).

The term "using a source of medical knowledge" means that physicians state they use at least one of the following sources: read e-journals, search through PubMed or similar publications, and keep on reading health portals. According to this definition the first place in using e-sources of medical knowledge belongs to physicians from private offices, $86 \%$. The second place belongs to physicians working within health centers, $79 \%$, while physicians coming from offices under lease use most rarely such sources of medical knowledge, $60 \%$. Figure 1 shows frequency of use of different electronic sources of medical knowledge based on types of practices.

Patterns of use of ICT are equal for all three groups of medical doctors: using e-mail was on the top, keeping on reading health portals was on the second place. Then searching medical literature through PubMed, Current Contents etc., and electronic journals like Croatian Medical Journal, British Medical Journal and alike follows. Differences in use of electronic sources of medical knowledge within physicians from the three types of offices are statistically significant (Chi-square test $p=0.043$ ).

Table 1. Medical doctors specializing in family medicine.

\begin{tabular}{|c|c|c|c|}
\hline & $\begin{array}{c}\text { Age } \\
\text { median (interquartile } \\
\text { range) }\end{array}$ & $\begin{array}{c}\text { Years of working } \\
\text { median (interquartile } \\
\text { range) }\end{array}$ & $\begin{array}{c}\text { Having a computer in his/her } \\
\text { office (\%) }\end{array}$ \\
\hline Office under lease & $43(41-46)$ & $15(12-19)$ & 62 \\
\hline $\begin{array}{c}\text { Office within a health } \\
\text { centre }\end{array}$ & $35(32-37)$ & $5(2-7)$ & 91 \\
\hline $\begin{array}{c}\text { Completely private } \\
\text { office }\end{array}$ & $43(41-44)$ & $15(7-19)$ & 91 \\
\hline
\end{tabular}


The term "using a source of medical knowledge" means that physicians state they use at least one of the following sources: read e-journals, search through PubMed or similar publications, and keep on reading health portals.

According to this definition the first place in using e-sources of medical knowledge belongs to physicians from private offices, $86 \%$. The second place belongs to physicians working within health centers, $79 \%$, while physicians coming from offices under lease use most rarely such sources of medical knowledge, $60 \%$. Figure 1 shows frequency of use of different electronic sources of medical knowledge based on types of practices.

Having some kind of an information system installed in computers in their offices, physicians use it primarily for administration: reporting, prescriptions, sick leaves, referrals and for billing (Figure 2). Usage of ICT in medical work (electronic medical records) was found at just above average $50 \%$ of physicians. But, as a rule, they have also "papers". That is doubling documentation as a result of a current legislative in the Republic of Croatia. Doing research based on information stored in e-format in their information system, is conducting just by $32 \%$ of physicians having an electronic medical record in their practice. In spite of prevailing of physicians from private offices, there are no statistically significant differences. Using an information system in their practices, $35 \%$ of 97 physicians evaluate their work (whatever it assumes). Also, there is no statistically significant difference between types of practices.

Satisfaction with the current status of computerization of primary health care is more than modest, only $19 \%$, considering the whole sample of physicians having some ICT application in their practice. In the same time, information needs are covered just partially. $32 \%$ of physicians said they can get enough information by using their information system. $40 \%$ of physicians feel that ICT gave more efficiency to their work, and $25 \%$ of physicians feel their patients are more satisfied since the information system was put to function.

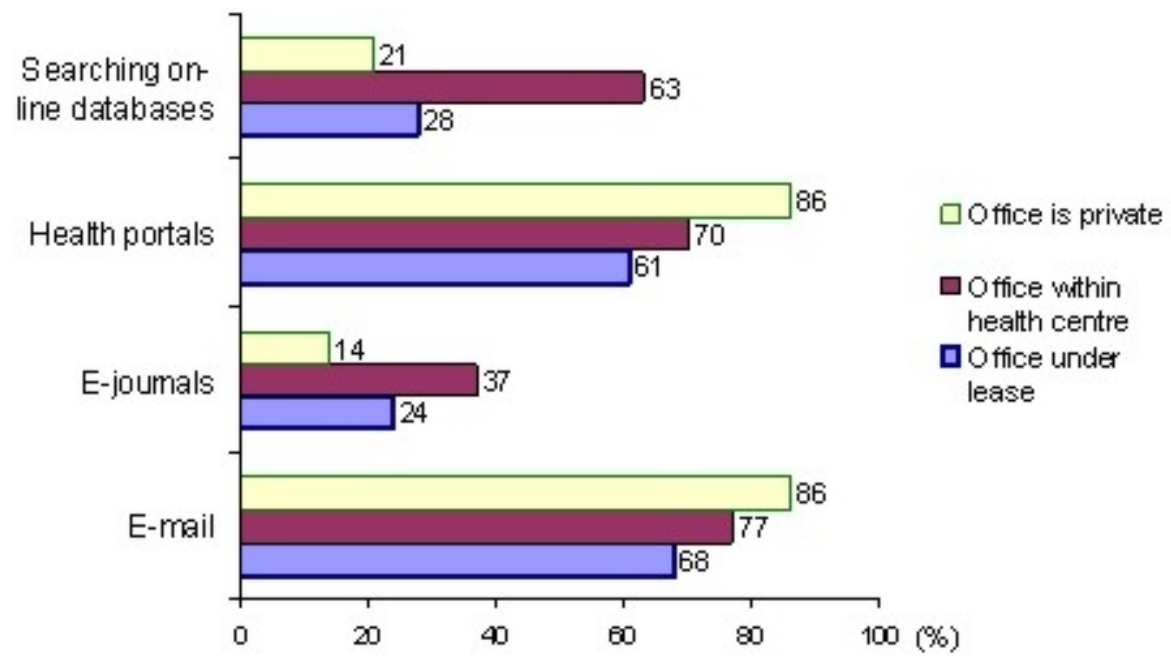

Figure 1. Frequency of using ICT by physicians specializing in family medicine.

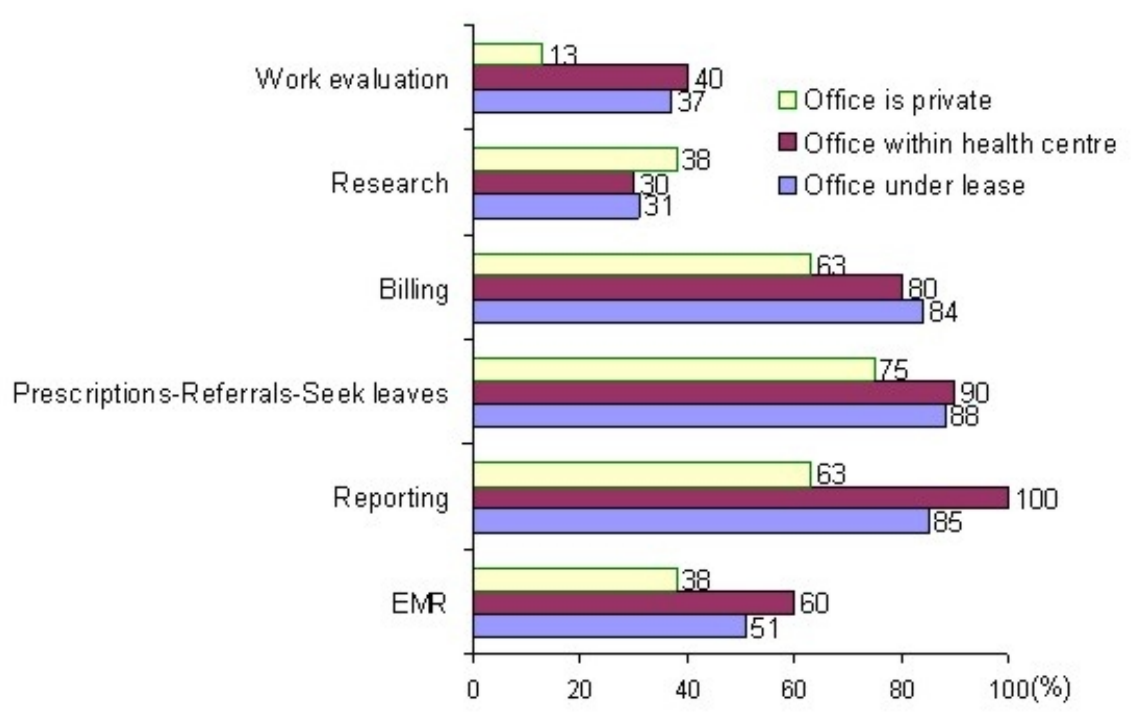

Figure 2. What for the ICT applications in family medicine practice are used.

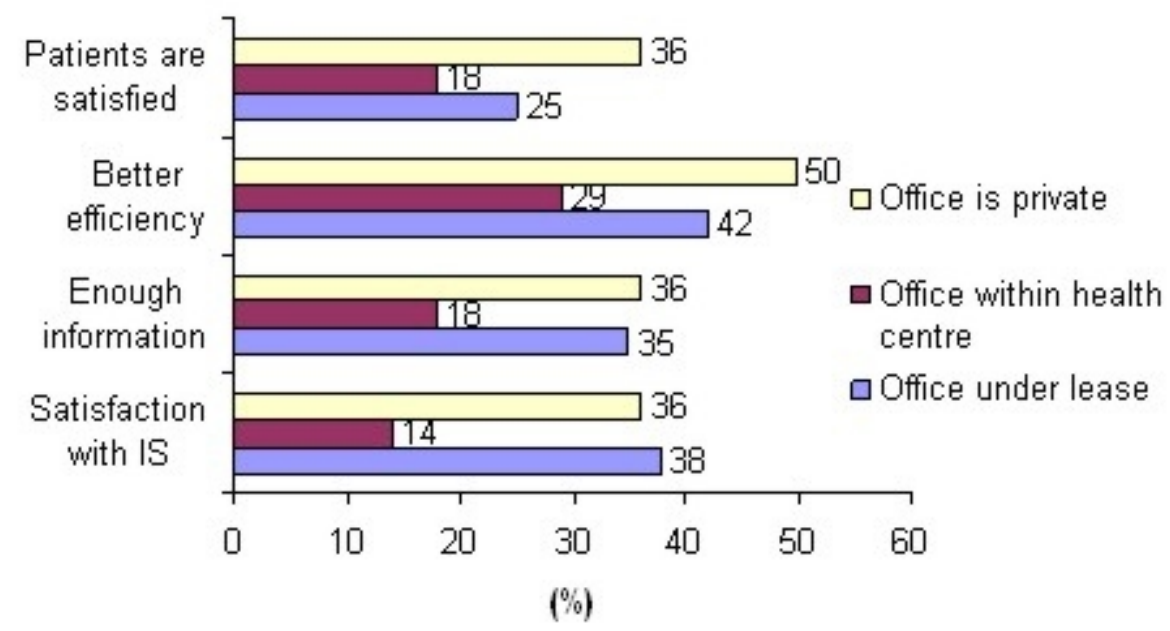

Figure 3. Satisfaction with ICT-based appliction - physicians' estimate. 


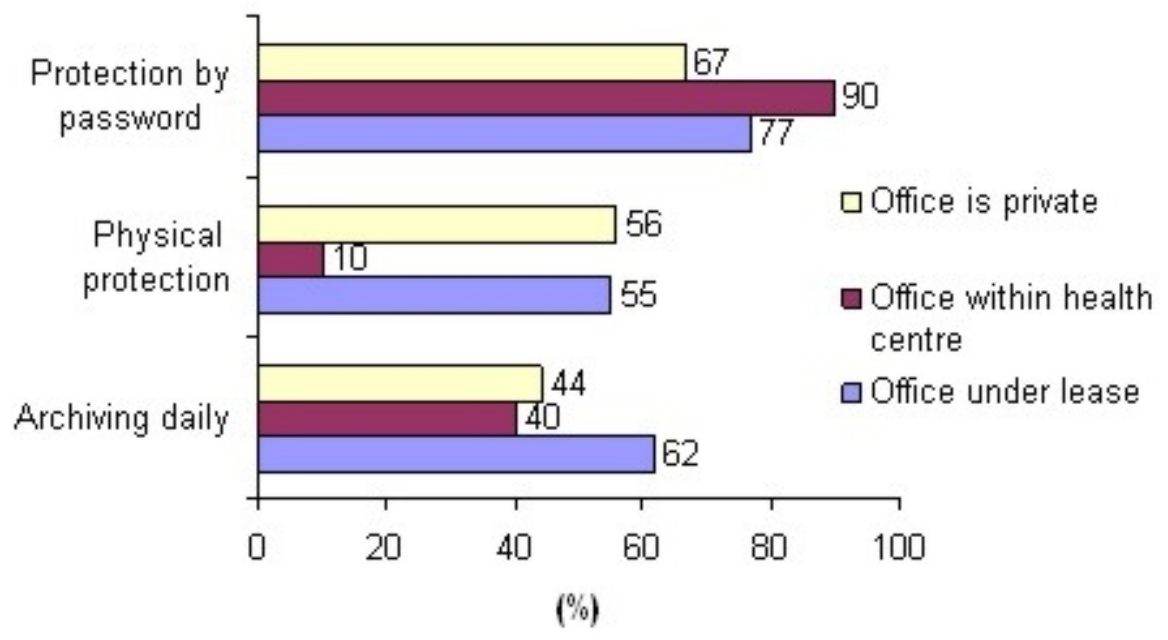

Figure 4. Data security in the information systems.

Considering different types of practices (Figure 3) there are some differences. Young physicians working in their offices within health centers are globally less satisfied with their information system then the other two groups of physicians coming from private practice (under lease or completely private offices).

Quality of data security in the information system was estimated through a) using a password, b) physical protection, and c) by archiving of data daily. There are statistically significant differences between types of practice considering physical protection (Chi-square test $p=0.028$ ). Daily archiving and protection by a password is nearly the same.

\section{Discussion}

Croatian physicians in family medicine practice use ICT less than those in developed countries [7]. Practicing family medicine physicians use ICT applications primarily for reporting and administration, and it is the same as in developed countries [7]. Information needed for health care and curing of a particular patient, do not have priority in informatization of the family practice. It is the same with information being supposed to improve their work through evaluation and research. For all this the basis is, of course, electronic medical record. Nowadays, the Croatian law requires the classical paper record. As a consequence, with electronic medical records, physicians must have also corresponding conventional paper records. It means double documentation. Doubling the work does not encourage physicians to use and improve electronic records. Therefore these records are mostly unstructured, mostly free texts what makes difficulties in any analysis.

Satisfaction with the current information system is pretty small. Only physicians in privately own practices are satisfied with their efficiency with using the information system. In the same time they positively evaluate patients' satisfaction with practices using some kind of an information system.

Security and safety of information systems can be discussed from different aspects. Avery and co-authors are saying on coordinating the most important elements of system safety from the point of view of clinical work (warnings whenever it needs, safety in repeated prescribing, etc.) [8]. Honyeman and co-authors discuss potential access to personal electronic medical records by patients themselves [9]. In age of new technologies, like the Grid-technology enabling to build and access distributed electronic records, it is necessary to consider more than ever security, safety and ethics [10], [11]. Safety of information in the family medicine practices information systems in Croatia is not good enough. Based on physicians' evaluation, less than $50 \%$ of physicians protect their e-information to a satisfactory level. However, it is a very rough estimate.

Considering the results of this survey, physicians working in family medicine practices are not skilful enough (or engaged) in using the information and communication technology in their professional work. Although they found Internet very useful (like in developed countries) and use e-mail and "surf" the Internet, they do not read enough professional electronic journals and secondary publications either. However, it is similar as in developed countries [12]. There is a little increase among younger physicians employed in (yet not-privatized) practices within health centers. It can be recognized as a hope that ICT using is getting better.

On the other side some physicians invest a lot in improving their work and relationship to the patients using the contemporary technology. There are several positive examples of taking information technology courses. These courses are organized by Medical Schools, Croatian Chamber of Physicians, but also by certain companies acting as vendors for such a technology. The Web technology is used for advertising practices. In the same time there are family physicians trying to appear "friendly" to patients, informing them on health and teaching them how to be healthy [13].

\section{Acknowledgement}

The authors would like to thank to Professor Milica Katić, professor of family medicine at the School of Medicine, University of Zagreb, who helped us to explain specificity of family practice organization in the Croatian health care system.

\section{References}

[1] Končar M., Gvozdanović D.: Primary Healthcare Information System - the Cornerstone for the Next Generation Healthcare Sector in Republic of Croatia. Int J Med Inform 2006; 75, pp.306-314.

[2] Kern J., Strnad M.: Informatics in the Croatian Health Care System. Acta Med Croatica 2005; 59, pp. 161-168. [in Croatian] 
[3] Golec B, Krajačić S.: Project of Automated Data Processing for Outpatient Health Organization. Health Centre RemetinecZagreb. Zagreb, Centre for economic development of the city of Zagreb, 1980. [in Croatian].

[4] Rosandić D.: Report on Introducing Computerization in the General Hospital "Dr. J.Kajfeš" - Zagreb, Zagreb, Commision for computerization of health care system 1975. [in Croatian].

[5] Reform of Healthcare System: Strategy and Plan of Reform of Health and Health Insurance System in Croatia. Zagreb, Ministry of Health 2002. [in Croatian]

[6] Stevanović R., Stanić A., Varga S.: Information System in Primary Health Care,
Acta Med Croatica 2005; 59, pp. 209-212. [in Croatian].

[7] Western M. C., Dwan K. M., Western J. S., Makkai T., Del Mar C.: Computerisation in Australian General Practice. Aust Fam Physician 2003;32, pp. 180-5.

[8] Avery A.J.,.Savelyich B.S, Sheikh A., Cantrill J., Morris C.J., Fernando B., Bainbridge M., Horsfield P., Teasdale S.: Identifying and Establishing Consensus on the Most Important Safety Features of GP Computer Systems: e-Delphi Study, Inform Prim Care 13 (2005) 3-12.

[9] Honeyman A., Cox B., Fisher B.:.Potential Impacts of Patient Access to Their Electronic Care Records, Inform Prim Care 2005; 13, pp. 55-60.
[10] Kalra D., Singleton P., Milan J., Mackay J., Detmer D., Rector A., Ingram D.: Security and Confidentiality Approach for the Clinical E-Science Framework (CLEF), Methods Inf Med 2005; 44, pp. 193-197.

[11] Claerhout B., De Moor G. J.: Privacy Protection for HealthGrid Applications. Methods Inf Med 2005; 44, pp. 140-143.

[12] Bennett N. L., Casebeer L. L., Kristofco R., Collins B. C.: Family Physicians' Information Seeking Behaviors: a Survey Comparison with Other Specialties. BMC Med Inform Decis Mak 2005; 5, p. 9.

[13] http://www.ordinacije-lazic.hr/. Accessed on August 14, 2006. 